\title{
Planning Strategic Sustainable Development in
}

\section{Malaysia by Incorporating the Concept of Low Carbon Society}

\author{
Janice J. Simson ${ }^{1}$, Ho Chin Siong ${ }^{2}$, Yuzuru Matsuoka ${ }^{1}$ and Kei Gomi ${ }^{1}$ \\ 1. Graduate School of Engineering, Kyoto University, Kyoto 615-8540, Japan \\ 2. Faculty of Built Environment, Universiti Teknologi Malaysia, Johor 81310, Malaysia
}

\begin{abstract}
Malaysia has undergone rapid urbanization and economic growth for past decades and is expected to continue to have an average economic grow at 5\%-6\% per annum in the next five years. This phenomenon of growth and pursuit of socio-economic progress has great impact not only on the economy but also on community life style and environment. The concept of sustainable development was adopted by Malaysia government as early as mid 1990s to address some of the emerging environmental issues and more specifically on climate change issues recently. Malaysia government announced a commitment of voluntary $40 \%$ reduction in $\mathrm{CO}_{2}$ emission intensity by 2020 during the Conference of Party (COP15) meeting in Copenhagen in 2009. In parallel to this commitment of $\mathrm{CO}_{2}$ emission reduction, the concept of sustainable development in urban planning should incorporate a more comprehensive and quantitative approach in the preparation of development plan as well as in exercising the routine development control practice at the local planning authority. This paper prepares a quantitative scenario study on the establishment of low carbon society in Iskandar Malaysia.
\end{abstract}

Key words: Sustainable development, environmental planning and low carbon society, Iskandar Malaysia.

\section{Introduction}

In 1987, Gro Harlem Brundtland in her report on "Our Common Future" has defined sustainable development as "development that meets the needs of the present without compromising the ability of future generations to meet their own needs". For more than two decades since then, world leaders have been making efforts towards making development sustainable. However, sustainability and climate are not the factors used to measure neither the national economy nor the health of the nation [1]. The world's economy is still highly influenced by the price of oil. If the world is pictured to be a system which is connected by time and space, people can understand as to how something that happens in the northern regions, such as air pollution can affect the air quality

Corresponding author: Janice J. Simson, post-doctoral researcher, research fields: climate change and low carbon society studies. E-mail: janicejsimson@gmail.com. in the southern regions, or how a conflict in the east could affect the peace in the west. On a smaller scale, take for example, a nation which has invested in green technology for transportation and has a good public transportation service and network [2]. This will lower the use of private vehicles, thus help reduce the amount of fuel combustion, which will lead towards lowering the energy consumed in this nation. In return, this will not just lower the $\mathrm{CO}_{2}$ being emitted into the atmosphere, but also make communing a convenience for to the general population. The evolution of energy resources has brought mankind a long way, from the discovery of fire, to the transition to fossil fuel and, the progression towards the use of electricity [3]. For better or for worst, the authors have seen the effects of these resources towards people's daily lives. The new global norm is the move towards the use of renewable and green technology [4]. The transition towards this new global norm will take time, but the point is that 
people have to stay at it, and the whole world needs to work together towards this.

The lowering of $\mathrm{CO}_{2}$ emissions is not just focused towards the goal of reducing the effects of climate change, but it is also an important move towards sustainable development. Here, the authors will explore what a LCS (low carbon society) is and how this can be entwined into the planning practices in Malaysia towards sustainable development. This paper aims to explore the application of the concept of LCS in Malaysia. The authors will also present a case study to examine the scenarios towards the reduction of $\mathrm{CO}_{2}$ emission in the Iskandar Malaysia. The EXSS (Extended Snapshot) tool is used in this study to calculate the $\mathrm{CO}_{2}$ emission reduction by measures. This tool and the methodology is further explained in section four of this paper.

\section{Sustainable Development in Malaysia}

Malaysia is a fast developing nation within South East Asia, lies on the equator. It covers a land area of approximately 329,750 km, consisting of Peninsular Malaysia and the states of Sabah and Sarawak. The 10th Malaysian Plan indicates the population of this multicultural and multiethnic county to be about 28.3 million in 2010 with a population growth rate of $1.3 \%$
(2006-2010), and has a GDP (gross domestic product) growth rate of 5.7\% per annum (2006-2008) [5]. The urban population consists of about $63 \%$ of the total population [6]. More than half of the total land areas of Malaysia (59.9\%) are forests which function as a carbon sink. Malaysia has various new strategies and development plans in line with Prime Minister, The Most Honourable Mohd Najib bin Tun Haji Abdul Razak's that aim to achieve the ambitious goals of Vision 2020 which were committed in year 1991. One of the main aims here is for Malaysia to economically transform to join the select group of high income nations. To formulate this into actions, the government has come out with the economic transformation plan, the 10th Malaysian Plan and various other development plans which build upon policy direction, strategies and programmes towards making this a reality. Together with this, Malaysia is also committed to a reduction of $40 \%$ in $\mathrm{CO}_{2}$ emission intensity by year 2020 compared with its 2005 levels, as delivered by the Malaysia Prime Minister in COP 15 in Copenhagen, Denmark in 2009 (Ministry of Green Technology, Energy and Water Malaysia (2010)) [7].

In the 10th Malaysian Plan, there are a total of five growth corridors identified as shown in Fig. 1. The

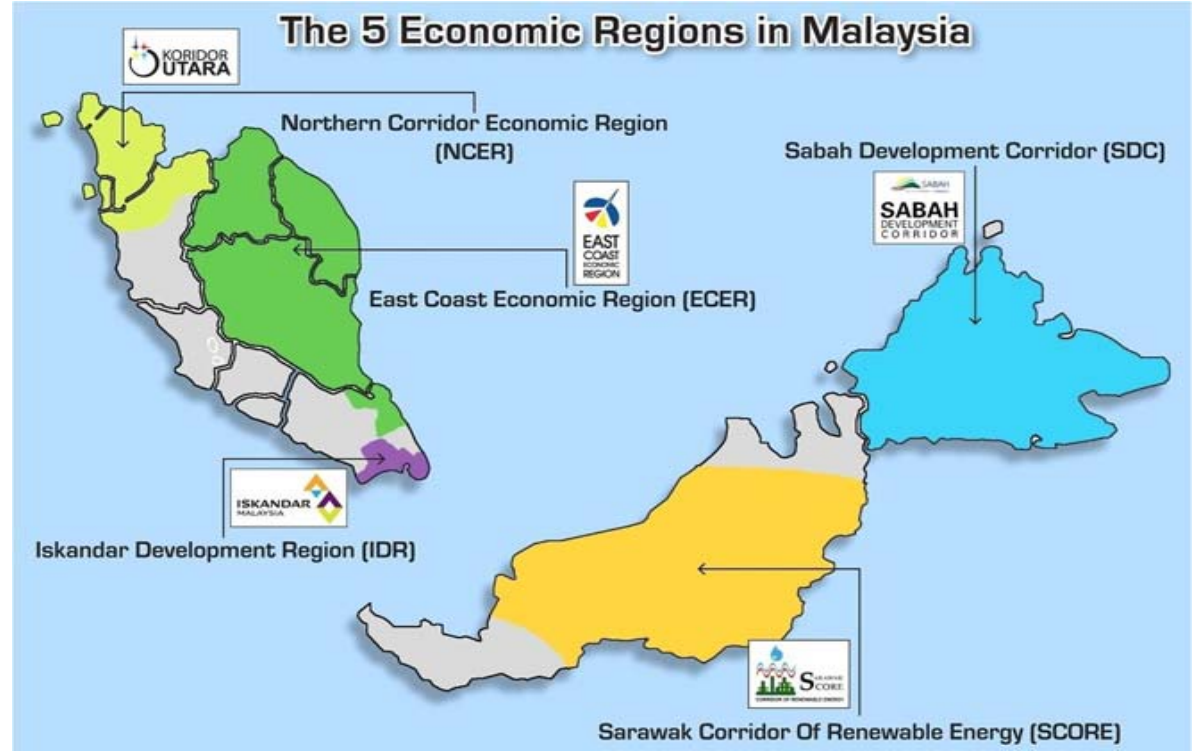

Fig. 1 Location of five (5) economic development corridors in Malaysia [5].

Source: National Physical Plan. 
planning of these urban agglomerations focuses on the development corridors around cluster and developing high economic sectors with clear competitive advantage to maximize impact based on common resources [8]. It also facilitates private investment to develop priority industries especially related to service industries. The limited number of high density cluster or conurbation of five main development corridors provides opportunities for urban planners to promote sustainable compact cities in line with low carbon city development principles.

The 10th Malaysia Plan (2011-2015), outlined two major national policies on environmental protection and conservation, i.e., National Green technology Policy (2009) and National Climate Change Policy (2009). The National Green Technology Policy emphasizes on sustainable development, development of roadmaps to guide the application of green technologies and also the establishment of GTFS (green technology financing scheme). However, national climate change policy will help to streamline and coordinate policy and legislation, stashed inter-ministerial and cross-sectoral committee to facilitate implementation and also to identify options and strategies to achieve low carbon economy EPU (Economic Planning Unit). Among the measures used in climate mitigation to reduce the carbon footprints are: (1) creating incentives for investments in renewable energy; (2) promoting energy efficiency to encourage productive use of energy; (3) improving solid waste management; (4) conserving forests; and (5) reducing emissions to improve air quality. Under the incentives for investments in renewable energy, the total renewable energy will be increased from < $1 \%$ or $41.5 \mathrm{MW}$ to $5.5 \%$ of the total generated electricity or 985 MW by 2015 .

With reference to the 2 NCR (Second National Communication Report) 2011 of the UNFCCC (United Nation Framework Convention on Climate Change), the current scenario of energy demand and $\mathrm{CO}_{2}$ emissions can be identified. The major proportion of commercial energy supply in 2000 and 2007 comes from oil and gas, $90.9 \%$ and $83.3 \%$, respectively, the other source of energy supply comes from hydropower and coke and coal. Table 1 shows the sector the trend of energy demand, transport sector marks the highest energy demand in 1990 with 5,387 ktoe, however, in 2007, the highest energy demand is from Industrial sector which is 19,116 ktoe. These two sectors are the key contributors towards the $\mathrm{CO}_{2}$ emission in Malaysia.

Fig. 2 shows the source of $\mathrm{CO}_{2}$ emission in Malaysia, a total of 167.44 Mton of $\mathrm{CO}_{2}$ was emitted. Emission from energy industries has the highest emission with $58.48 \mathrm{Mton}^{\mathrm{CO}_{2}}$, this is from industries who are the power and auto producers (self energy producers) for producing electricity, petroleum refining and natural gas transformation. However, second highest emitters are the transportation sector, and is followed by the manufacturing industries construction [9].

The calculation done for analysis in the 2NCR reflects LEAP modelling. The national population is estimated to reach 32.76 million by year 2020, and the GDP is expected to grow at a slower rate of about $4.9 \%$ per annum for the period of $2000-2020$. The

Table 1 Malaysian final energy demand by sectors (ktoe).

\begin{tabular}{lrrrrrr}
\hline Sectors & \multicolumn{1}{c}{1990} & 1995 & 2000 & 2005 & \multicolumn{1}{c}{2006} & 2007 \\
\hline Agriculture & \multicolumn{1}{c}{} & 446 & 104 & 101 & 258 & 281 \\
Non-energy & 908 & 2,994 & 2,250 & 2,173 & 2,809 & 2,958 \\
Residential and commercial & 1,646 & 2,837 & 3,868 & 5,134 & 5,430 & 6,196 \\
Transport & 5,387 & 7,827 & 12,071 & 15,384 & 14,825 & 15,717 \\
Industrial & 5,276 & 8,060 & 11,406 & 15,492 & 17,002 & 19,116 \\
Total & 13,217 & 22,164 & 29,699 & 38,284 & 40,324 & 44,268 \\
\hline
\end{tabular}

Source: Second National Communication (2011) [9] to the UNFCCC. 


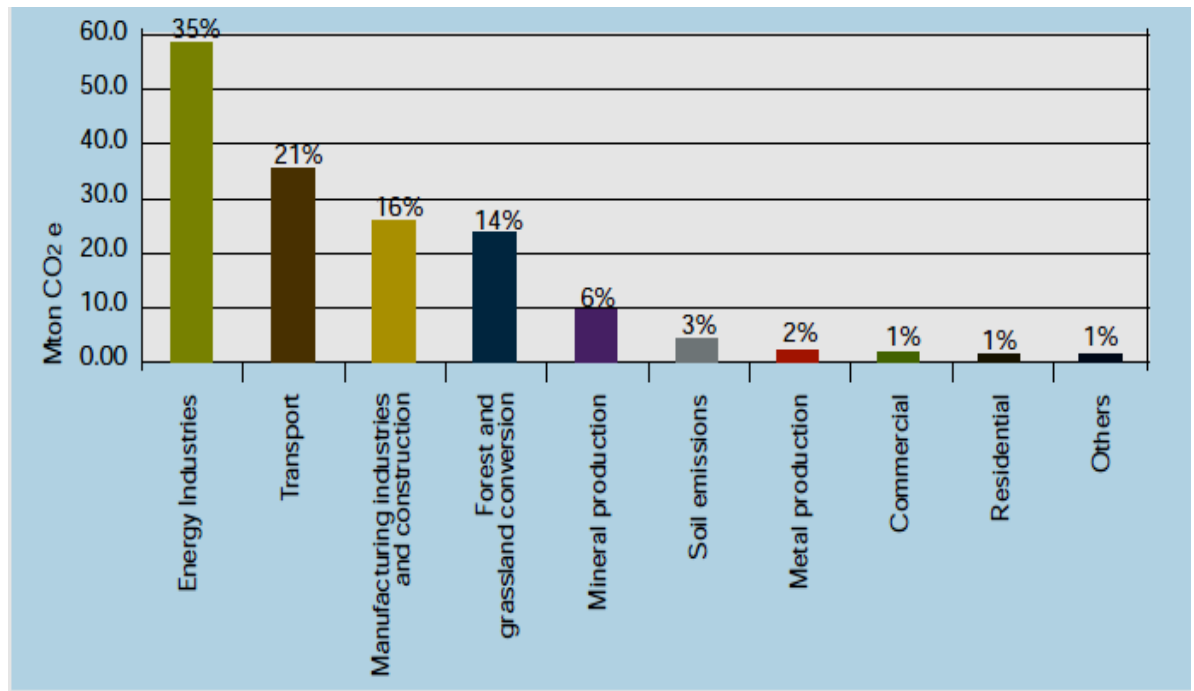

Fig. 2 Source of $\mathrm{CO}_{2}$ emission in Malaysia 2000.

Source: Second National Communication (2011) [9] to the UNFCCC.

estimation for the final energy demand for 2000-2020 can be seen in Fig. 3. The industrial and transportation sectors show an average annual growth rate of 5.0\% and $4.7 \%$, respectively. In the energy sector, there are three mitigation measures scenarios introduced, namely the EEC (energy efficient conservation), the $\mathrm{RE}$ (renewable energy) and the EEC+RE (total combination of assumptions). The $\mathrm{CO}_{2}$ emission under $\mathrm{BaU}$ scenario is expected to grow annually at about 3.72\% from 2000 to 2020 (Fig. 4). In the EEC scenario, the growth will be at $3.53 \%$, the RE scenario indicates a $3.49 \%$ annual growth. In the scenario which combines EEC and RE, the $\mathrm{CO}_{2}$, emission will be the least which is about 243 million tonne.

With regard to these findings, there are also mitigation measure which involves land use, land-use change and forestry to reduce the emission from the agriculture and forestry sectors. However, this section is not discussed in this paper.

\section{Case Study of Low Carbon Society}

The IM (Iskandar Malaysia) area covers about

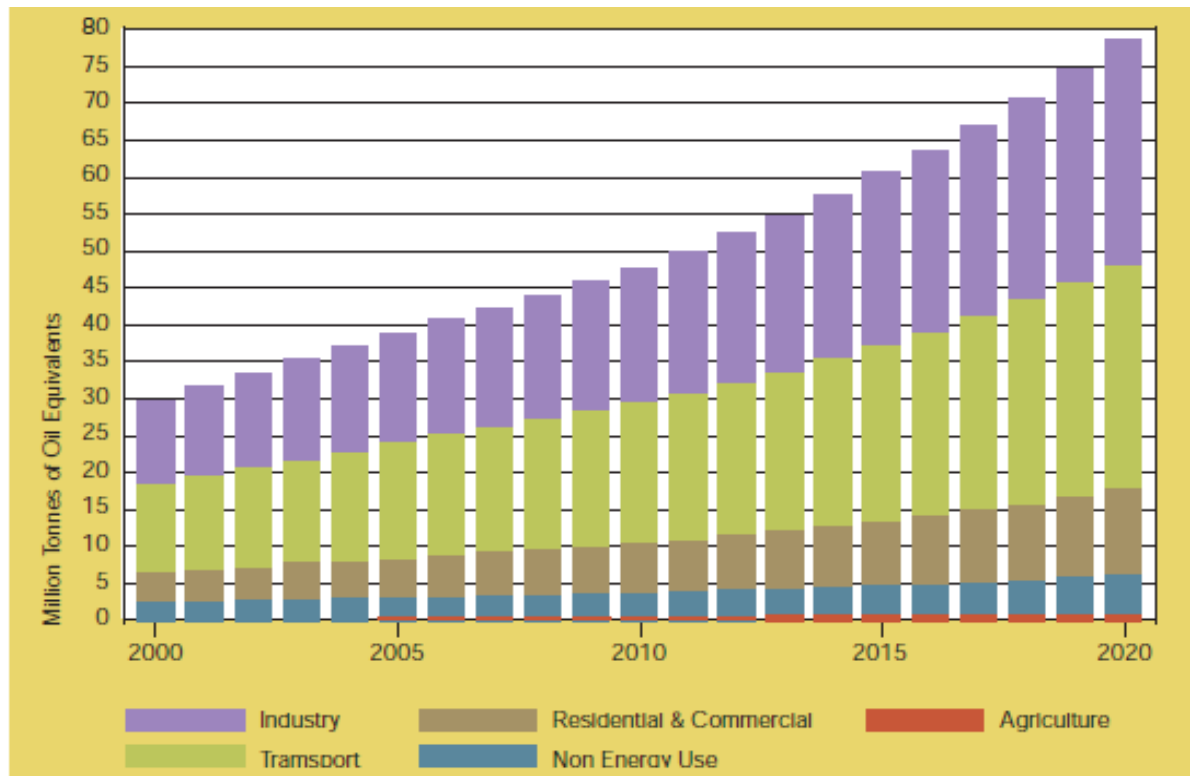

Fig. 3 Final energy demand by sectors in BaU (business as usual) scenario, 2000-2020.

Source: Second National Communication (2011) [9] to the UNFCCC. 


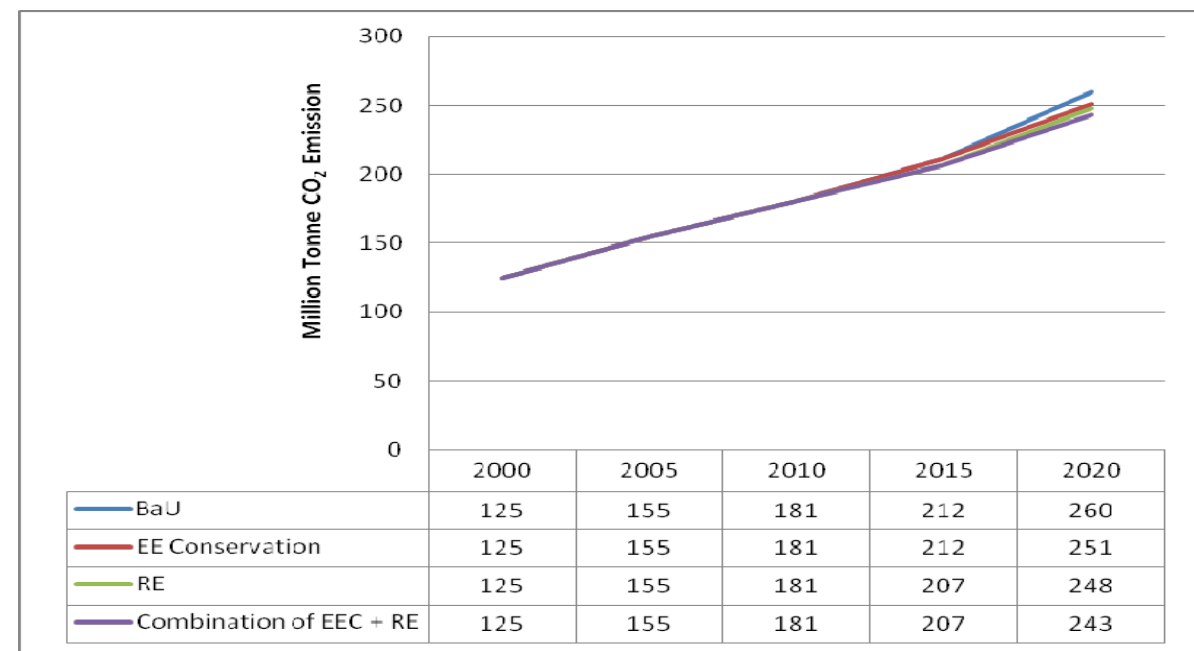

Fig. $4 \mathrm{CO}_{2}$ emission projection by scenarios, 2000-2020.

Source: Second National Communication (2011) [9] to the UNFCCC.

$2,216.3 \mathrm{~km}^{2}$, it is about three times the size of singapore and two times the size of Seoul Metropolitan Area. IM covers the entire district of Johor Bahru, and several sub-districts of Pontian. The planning area falls under the jurisdiction of five local planning authorities, namely Johor Bahru City Council, Johor Bahru Tengah Municipal Council, Pasir Gudang Local Authority, Kulai Municipal Council and Pontian District Council (Khazanah National (2006)) [10].

Iskandar Malaysia lies at the heart of South East Asia at the southern tip of Peninsular Malaysia and within minutes from Singapore. It is strategically located at the major cross roads of east-west trade routes of fast growing countries like China and India. From a regional perspective, the development of Iskandar will lend a greater competitive edge to the region and will benefit significantly from the air and sea linkages within Asia-Pacific countries. There are a total of five flagship zones (Fig. 5) proposed as key focal points for development within the IM area (Khazanah National (2006)) [10].

Currently, the two main economic growth sectors in IRDA (Iskandar Regional Development Area) are manufacturing and services. The key sectors in the manufacturing sector that drive the IDR economy are electrical and electronic ( $\mathrm{E} \& \mathrm{E}$ ), chemical and chemical products (petrochemical, plastics and oleo chemicals) and food processing sub-sectors. They contribute $60 \%$ of the total value added in manufacturing. These key sectors lead to the emergence of supporting or induced sectors such as retail, wholesale, hotels, restaurants and finance. In manufacturing, the induced sectors include fabricated metal products, non-metallic products and transportation equipment [11].

There are three main policies as stated in the master plan for IDR that known as the Comprehensive Development Plan for South Johor Economic Region, 2006-2025 (hereinafter referred as “CDP”), which have direct impact on low-carbon scenario of the IDR development. Among these policies are energy efficient building, sustainable land use and transportation, and natural and green environment (Khazanah National (2006)) [10].

\section{Methodology}

LCS can be defined as a society that consumes sustainable and relatively low-carbon energy as compared with the present day practice, this is to avoid adverse climate change. Conscious efforts need to be taken by communities, industries, institutions and the government to change their behaviour towards energy consumption and supply. The society will adopt 


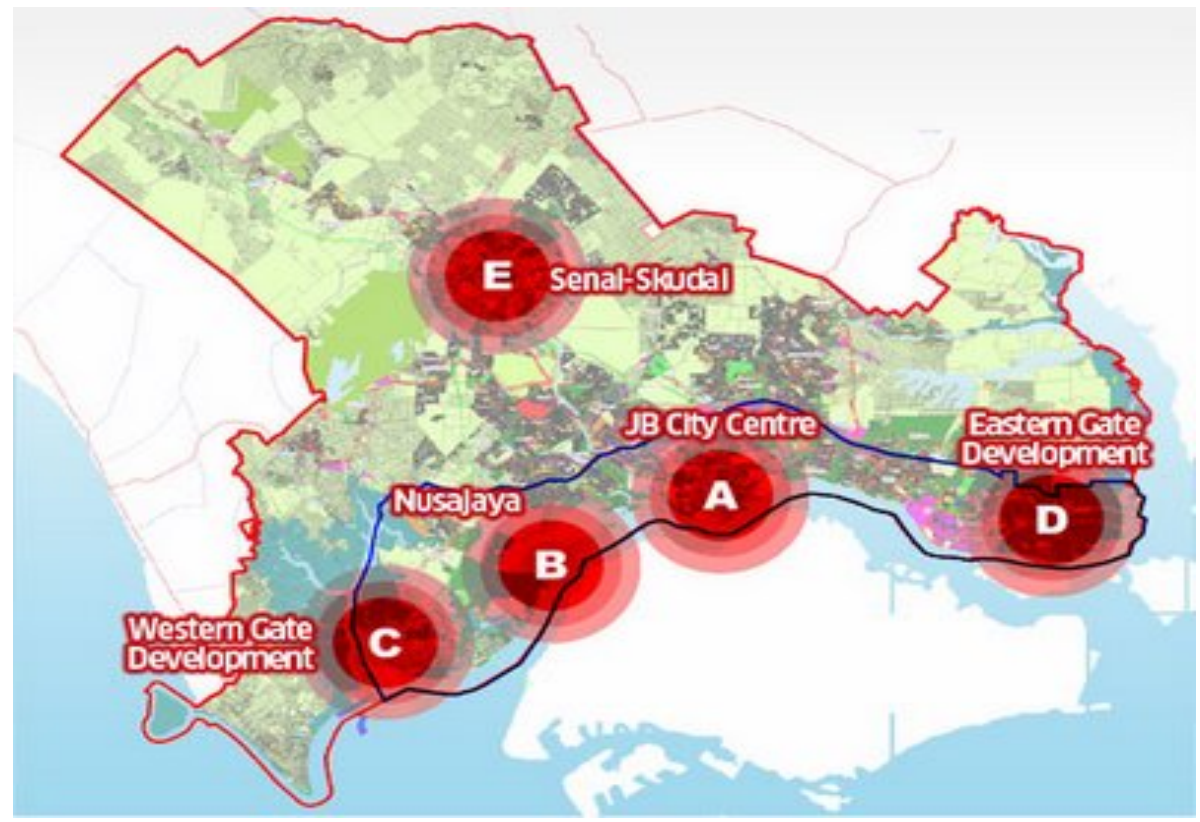

Fig. 5 Flagship zones within Iskandar Malaysia.

Source: Comprehensive Development Plan (2005-2025).

a lifestyle which uses more alternative renewable energy and is less dependent on fossil fuel, it will also practice the 3R (Reduce, Reuse and Recycle) in their everyday life.

There are seven steps towards developing the LCS scenario using a back casting method. Fig. 6 shows the steps. Setting of the framework is a very important step, this is when the base year and the target year are determined. The base year for this study is set by identifying the availability of data for IM and the target year is set as 2025 based on the future development plans identified for IM from the CDP (Comprehensive Development Plan) of Iskandar Malaysia.

In this study, the $\mathrm{CO}_{2}$ emissions of Iskandar Malaysia are estimated using a quantitative tool identified as the "EXSS tool". This model uses regional economic model to estimate energy demand and $\mathrm{CO}_{2}$ emission by five main sectors, namely industry, residential, commercial, passenger and freight transport and power [12].

Fig. 7 shows the structure of model whereby it involves seven blocks with input parameters exogenous variables and variables between modules.
In this simulation model, $\mathrm{CO}_{2}$ emission from only energy consumption is used in the calculation. For the LCS scenarios, exogenous variables such as fixed population data are used. The projection of population is determined by the demand from outside the region, because Iskandar Malaysia is a planned regional corridor development. In order to determine the output of industries, the input-output model with export base approach are used. Industries producing export goods are grouped as basic industry. Production of basic goods induces other industries, i.e., non basic, through demand of intermediate input and consumption of the employees [14]. Number of workers can be estimated

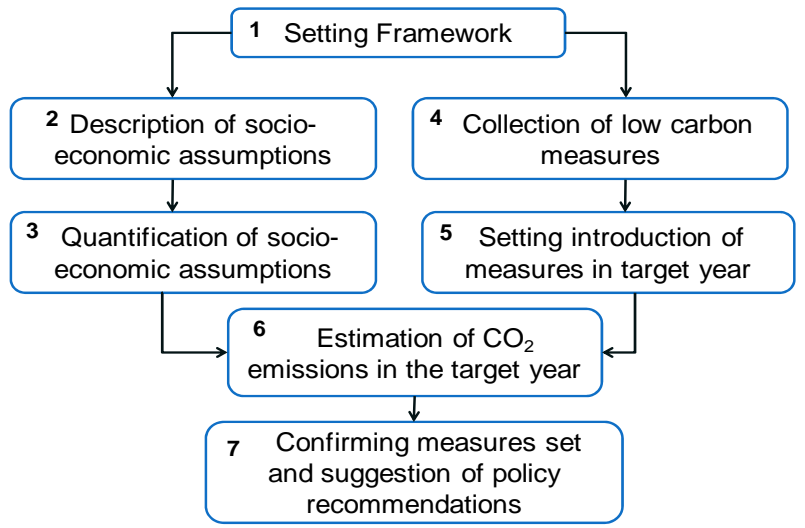

Fig. 6 Steps in developing low-carbon scenarios. 


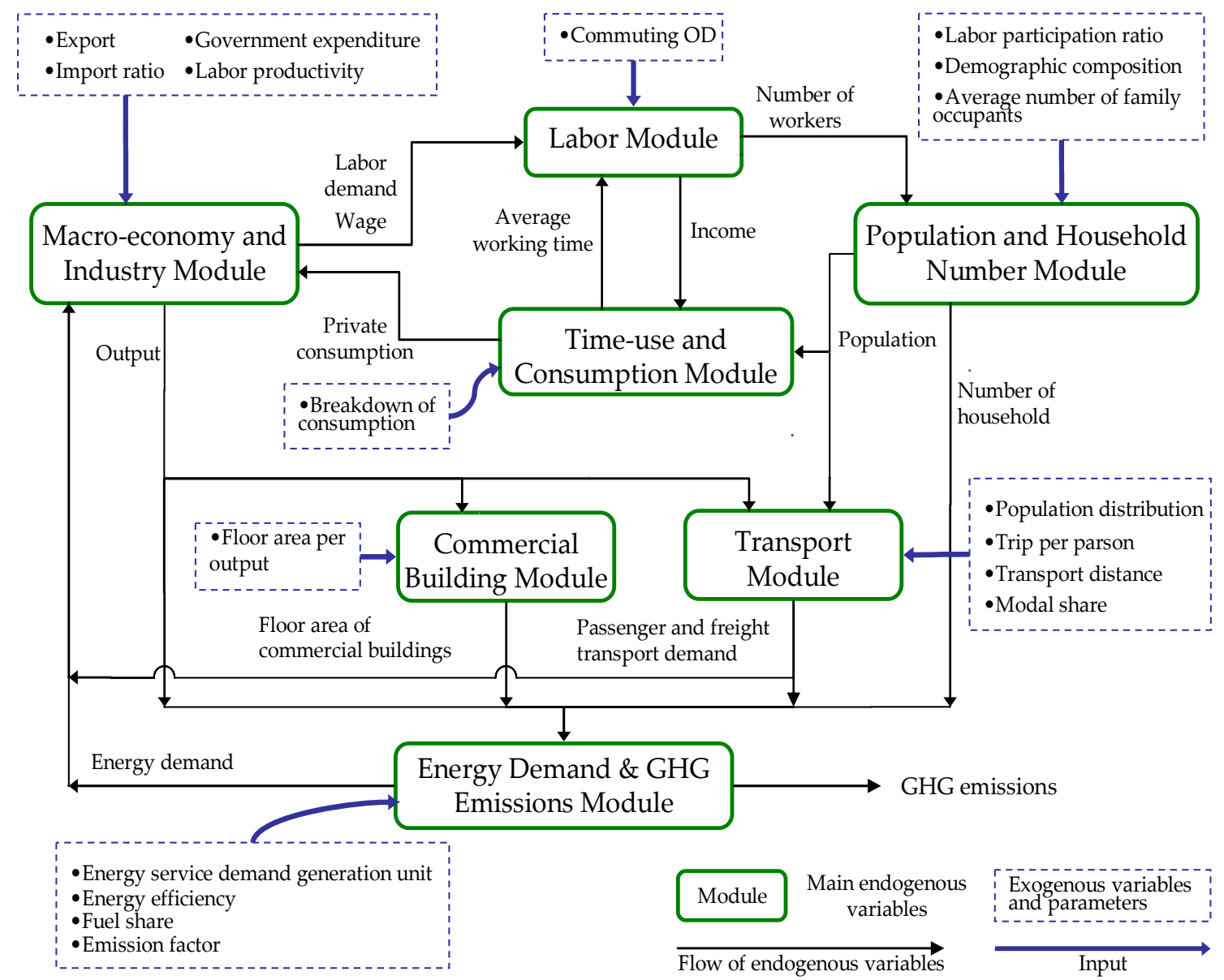

Fig. 7 Overview of computation system of extended snapshot tool [13].

to meet labor demand of those productions. Given the assumptions where those workers lived and lab our participation ratio, population in the region can be computed.

Passenger transport demand is calculated from population data. However, in order to calculate the freight transport demand, it is a function of output of manufacturing industries, floor of commercial areas is determined from output of tertiary industries. The activity level of each sector, energy demand by fuels is determined by three parameters, i.e., energy service demand, energy efficiency and fuel share [15].

The base year for this study on $\mathrm{CO}_{2}$ emissions from energy use in Iskandar Malaysia was 2005 and the target year is set at 2025. This is because most of the data used for the projection are from the secondary source of CDP (Comprehensive Development Plan)
2005-2025—South Johor Economic Region. The estimation of $\mathrm{CO}_{2}$ emission is based on energy consumption by sectors such as residential, commercial, industry and transport.

The estimated results of future socio-economic indicators and energy demand in 2025 are based on modeling of the socio-economic variables and energy balance table in 2025. The projection of $\mathrm{CO}_{2}$ emissions was carried out based on the following two scenarios:

(1) "business as usual” scenario (2025 BaU scenario), according to the various high population and economic targets adopted in the CDP (Comprehensive Development Plan) in the next 20 years;

(2) Scenario with mitigation or counter-measures (2025 CM Scenario), where assumptions of employed 
technologies as well as potential low-carbon measures to reduce $\mathrm{CO}_{2}$ emissions are available by 2025 .

Since EXSS calculates the amount of $\mathrm{CO}_{2}$ emission reduction by measure, a measure especially with high reduction potential or the local government's original policy can show the effect of the measure which is identified as important.

\section{The Socio-Economic Scenario of Iskandar Malaysia in 2025}

\subsection{Scenario Quantification}

The socioeconomic assumption in 2025 which is a required for the estimation of energy demand and $\mathrm{CO}_{2}$ emission is estimated here. The scenario descriptions are estimated by using a macroeconomic model. The estimated results are categorized as economy, establishment and transportation and are seen in Table 2 below. The population of IM in year 2005 is about 1.3 million and is estimated to grow about twice this size to have three million in population by the target year 2025. The gross domestic production is estimated to increase about 4.7 times from base year (2005), RM 36 billion to RM 166 billion in target year (2025).

Establishments are categorized as the number of households and, in IM it will increase from 318,000 (2005) to 750,000 (2025), the average household size in IM will decrease from 4.26 (2005) to 4.00 (2025). The total floor space of buildings in IM will increase from $4 \mathrm{~km}^{2}$ (2005) to $23 \mathrm{~km}^{2}$ (2025). The transportation category indicates that passenger transport demand in IM will increase about 2.2 times and, freight transport demand in IM will increase about 3.5 times. Currently the passenger transport demand in IM is dominated by private owned vehicles which comprise about $70 \%$ of the total passenger transportation. As for freight transport demand goods are mostly transported by road compared (99\%) to only about $1 \%$ of rail. However, with countermeasures, these scenarios will change towards a more energy efficient manner.

\subsection{Energy Demand and $\mathrm{CO}_{2}$ Emissions in Iskandar} Malaysia

The estimated results for energy demand by sector are illustrated in Fig. 8. In the base year (2005) scenario the industrial sector records the highest energy demand with 1,060 ktoe (kilo tonne oil equivalent) and this increase about $72 \%$ to reach 3,854 ktoe in $2025 \mathrm{BaU}$ scenario. Freight transportation is the sector with the second highest energy demand levels in base year and 2025 BaU with 553 ktoe and 1,947 ktoe, respectively. However, with countermeasures this sector will be able to reduce about 33\% of energy demand in 2025 LCS from BaU scenario.

This is because, there will be more rail based freight transportation being introduced as countermeasure. The passenger transportation sector records an increase of nearly 55\%, it records 441 ktoe in 2005 to 977 ktoe in 2025 BaU. With countermeasures, the energy demand in the passenger

Table 2 Estimation result of scenario quantification in 2025, Iskandar Malaysia.

\begin{tabular}{|c|c|c|c|c|c|}
\hline Item & Unit & 2005 & $2025 \mathrm{BaU}$ & 2025 LCS & \begin{tabular}{|l|l|}
$2025 \mathrm{BaU} / 2005$ & $2025 \mathrm{LCS} / 2005$ \\
\end{tabular} \\
\hline Population & '000 & 1,353 & \multicolumn{2}{|c|}{3,000} & 2.2 \\
\hline No. of households & '000 HH & 318 & \multicolumn{2}{|c|}{750} & 2.4 \\
\hline GDP & $\begin{array}{l}\text { bil. RM } \\
\text { bil. US\$ }\end{array}$ & $\begin{array}{l}36 \\
9\end{array}$ & \multicolumn{2}{|c|}{$\begin{array}{l}166 \\
44\end{array}$} & $\begin{array}{l}4.7 \\
4.7\end{array}$ \\
\hline Per capita GDP & $\begin{array}{l}\text { RM } \\
\text { US\$ }\end{array}$ & $\begin{array}{l}26,359 \\
6,971\end{array}$ & \multicolumn{2}{|c|}{$\begin{array}{l}55,404 \\
14,653\end{array}$} & $\begin{array}{l}2.1 \\
2.1\end{array}$ \\
\hline Floor space & $\mathrm{km}^{2}$ & 4 & \multicolumn{2}{|c|}{23} & 5.5 \\
\hline $\begin{array}{l}\text { Passenger transport demand } \\
\text { Freight transport demand }\end{array}$ & $\begin{array}{l}\text { mil. p-km } \\
\text { mil. t-km }\end{array}$ & $\begin{array}{l}11,994 \\
8,269\end{array}$ & $\begin{array}{l}26,591 \\
29,122\end{array}$ & $\begin{array}{l}26,364 \\
28,231\end{array}$ & $\begin{array}{l}2.2 \\
3.5\end{array}$ \\
\hline
\end{tabular}

Source: Comprehensive Development Plan (2005-2025). 


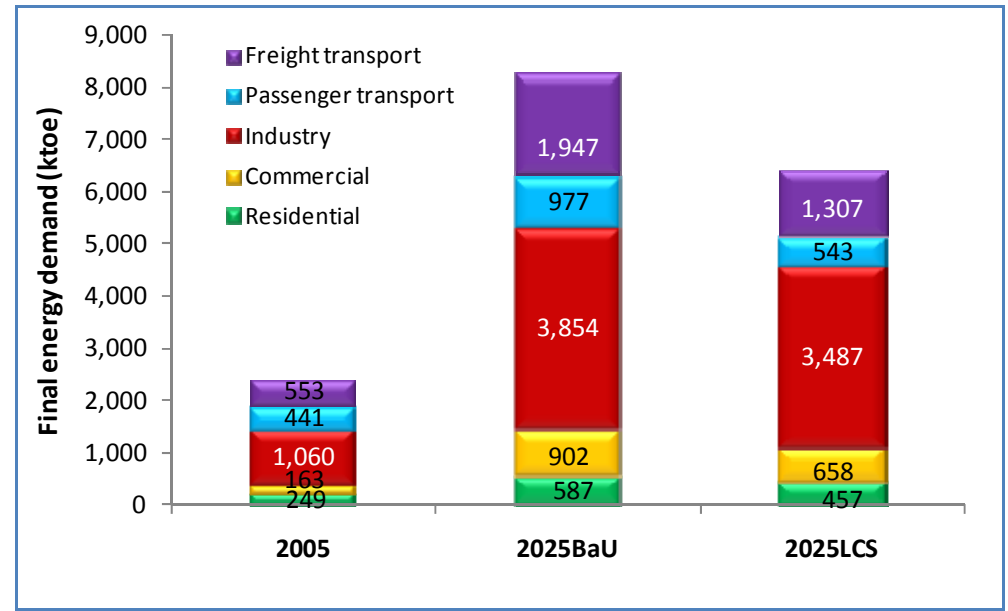

Fig. 8 Final energy demand by sector.

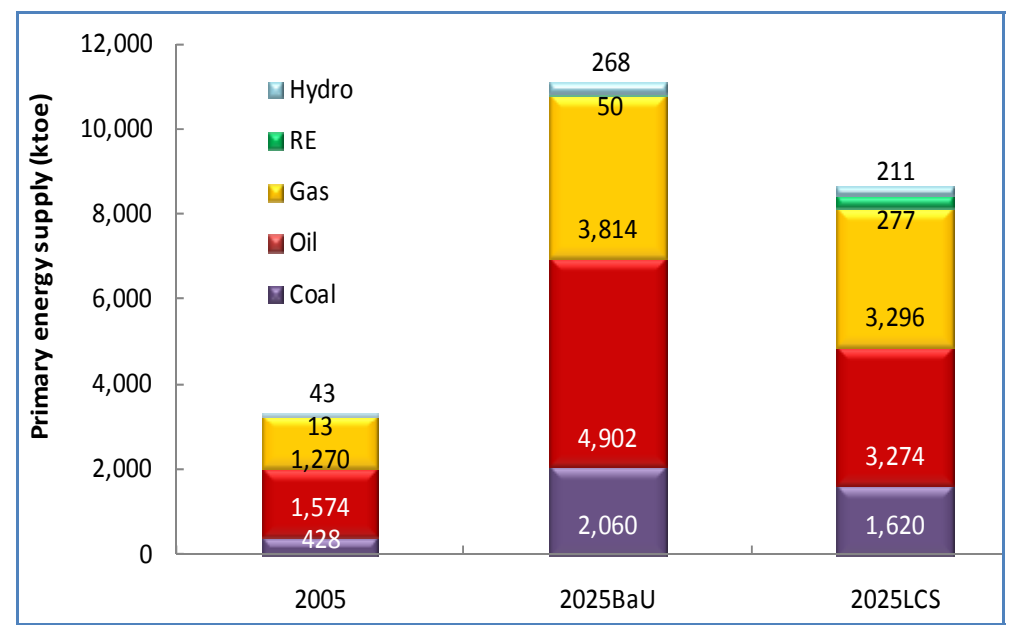

Fig. 9 Primary energy supply.

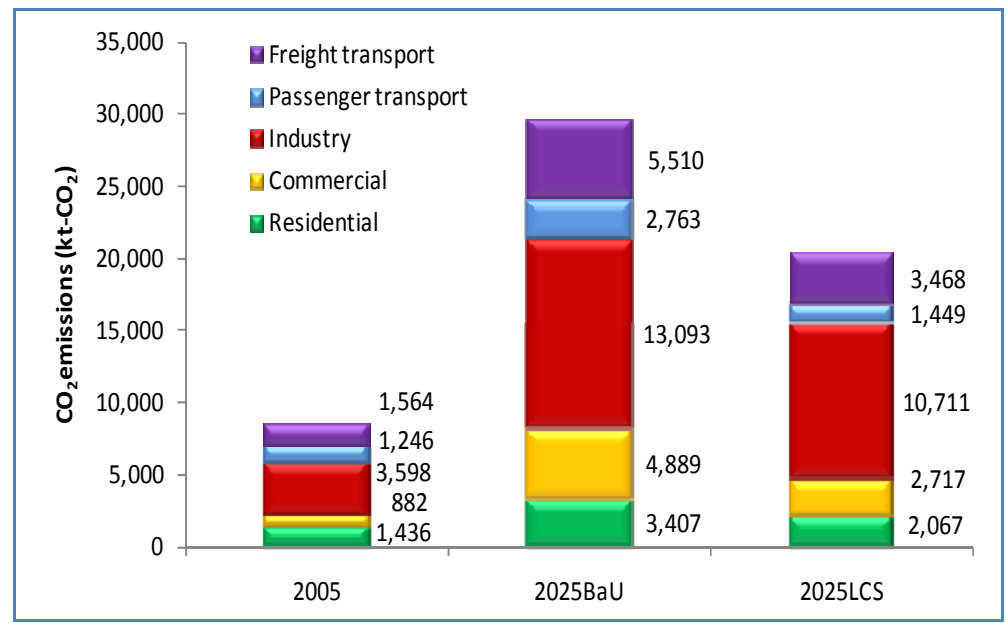

Fig. $10 \mathrm{CO}_{2}$ emissions by sector.

transportation sector can be reduced about $44 \%$ from BaU scenario. In 2025 LCS, there will be an increase in the usage of public transportation compared to the usage of private transportation.

Fig. 9 presents the primary energy supply in Iskandar Malaysia. Oil is identified as the main supply 
for energy in base year and both the scenarios in 2025. However, in 2025 BaU scenario energy supply from coal increases three times, where as oil and gas increase about two times from the base year scenario. In 2025 LCS, it is estimated that the usage of RE (renewable energy) will increase about 4.5 times from 2025 BaU scenario.

The $\mathrm{CO}_{2}$ emission by sectors in Iskandar Malaysia (Fig. 10) is estimated to be 8,726 kt- $\mathrm{CO}_{2}$ in 2005 and it is estimated to increase about 3.4 times to reach 29,662 kt- $\mathrm{CO}_{2}$ in $2025 \mathrm{BaU}$ scenario. With the appropriate countermeasures in 2025 LCS the emission can be reduced nearly $31 \%$ to reach 20,412 $\mathrm{kt}-\mathrm{CO}_{2}$. The emission reduction potential of each sector can be seen clearly in Fig. 11. The industrial sector can be seen as the highest contributor of $\mathrm{CO}_{2}$ emissions in all three scenarios. However, when studied carefully, the commercial sector is estimated to increase nearly 5.5 times in its emission size from base year to $2025 \mathrm{BaU}$, where as the industrial sector increases about 3.6 times and freight transportation increases about 3.5 times in the same time duration.

The per capita $\mathrm{CO}_{2}$ emission can be seen in Fig. 12 . There is an increase of per capita $\mathrm{CO}_{2}$ emission from 2005 to 2025 BaU about 35\%, and with countermeasures this emission is able to be reduced to $6.8 \mathrm{t}-\mathrm{CO}_{2} /$ person in $2025 \mathrm{LCS}$, this is a reduction of about 31\% from 2025 BaU. The $\mathrm{CO}_{2}$ emission intensity (Fig. 13) is $0.93 \mathrm{~kg} \mathrm{CO} / \mathrm{US} \$$ in 2005. The emission intensity is further reduced to $0.67 \mathrm{~kg}$ $\mathrm{CO}_{2} / \mathrm{US}$ \$ in $2025 \mathrm{BaU}$ scenario. In $2025 \mathrm{LCS}$, Iskandar Malaysia records a reduction of $50 \%$ from base year to achieve $0.46 \mathrm{~kg} \mathrm{CO} / \mathrm{US} \$$.

The per capita $\mathrm{CO}_{2}$ emission shows an increase from 2005 to $2025 \mathrm{BaU}$, while the $\mathrm{CO}_{2}$ emission intensity shows a reduction. This is because when $\mathrm{CO}_{2}$ emission is measured against the GDP of Iskandar Malaysia, a reduction is identified. This is the scenario for most developing countries which experience a growing GDP. The target of achieving a $50 \%$ in $\mathrm{CO}_{2}$ emission intensity in 2025 from 2005 levels is feasible, as it can be seen in the 2025 LCS in Fig. 10.

\subsection{Mitigation Potential of Iskandar Malaysia in 2025}

The reduction potential by measures type can be seen in Fig. 14. Efficiency improvement in the power generation sector is seen to have the highest contribution of reduction potential with 2,129 kt- $\mathrm{CO}_{2}$ reduction. This is followed by energy efficiency improvement in the freight transportation $(1,446$ kt- $\left.\mathrm{CO}_{2}\right)$ and commercial (1,196 kt- $\left.\mathrm{CO}_{2}\right)$ sectors, respectively. There is a total reduction of 9,250 kt- $\mathrm{CO}_{2}$ in $2025 \mathrm{LCS}$, and improvement in energy efficiency records the highest percentage in reduction type with 54\% of reduction potential. This is followed by efficiency improvement of power generation (23\%) and fuel switch (12\%). In order to realize a low-carbon

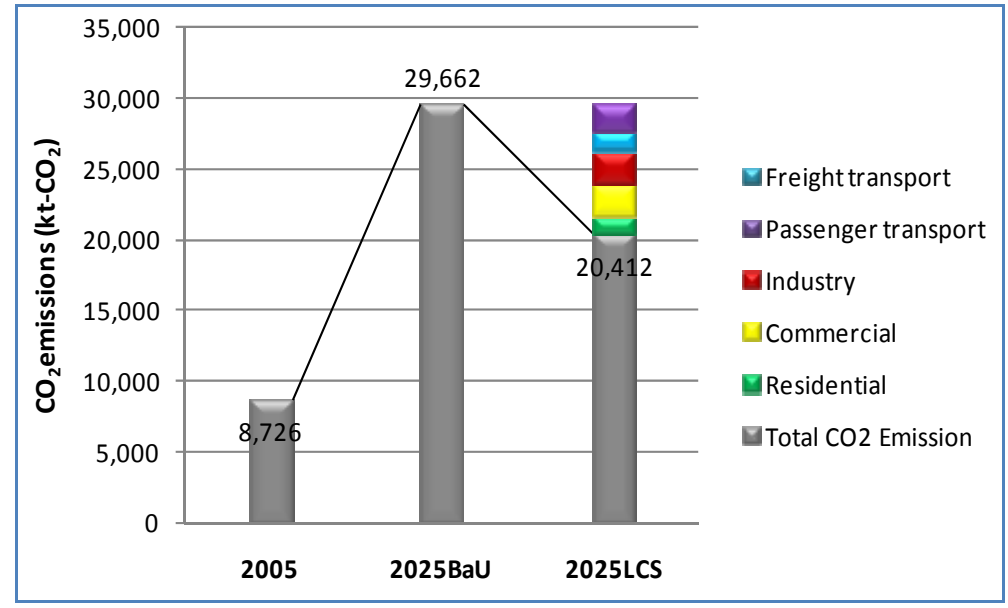

Fig. 11 Total $\mathrm{CO}_{2}$ emission reduction potential by sector. 

Incorporating the Concept of Low Carbon Society

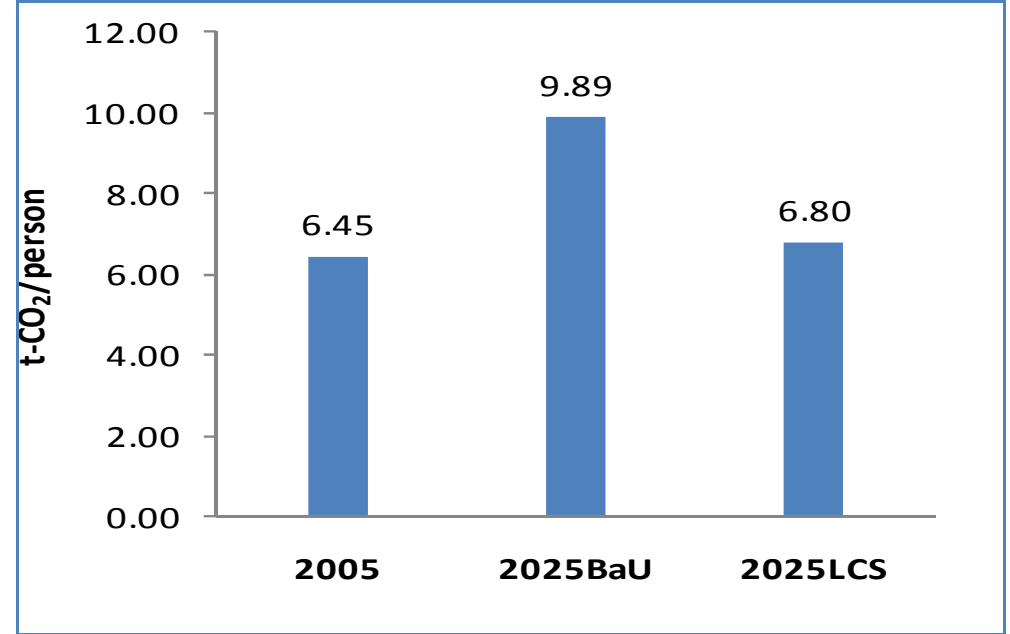

Fig. 12 Per capita $\mathrm{CO}_{2}$ emission.

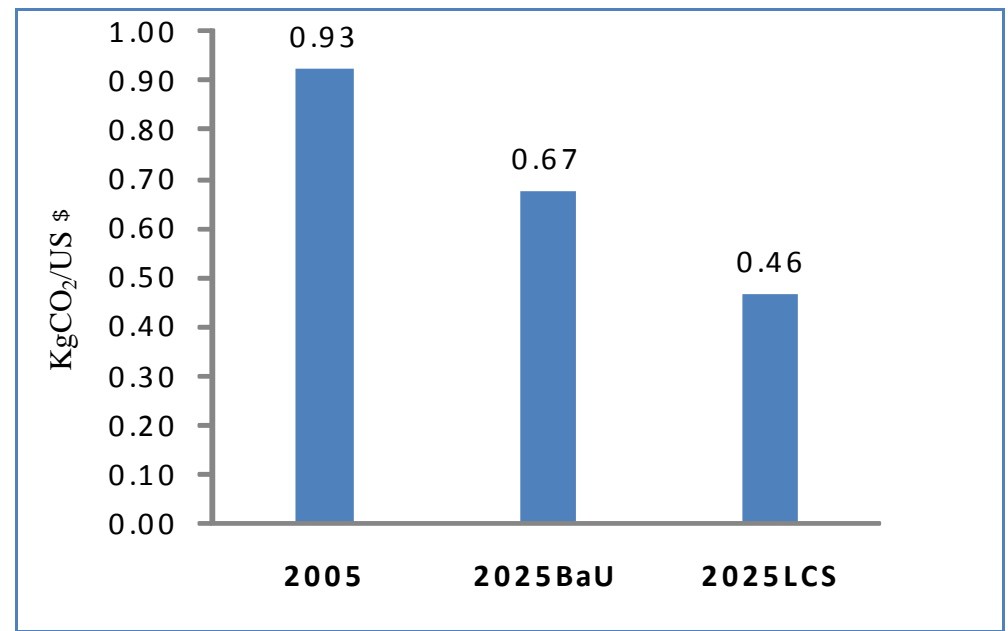

Fig. $13 \mathrm{CO}_{2}$ emission intensity $\left(\mathrm{CO}_{2} / \mathrm{GDP}\right)$.

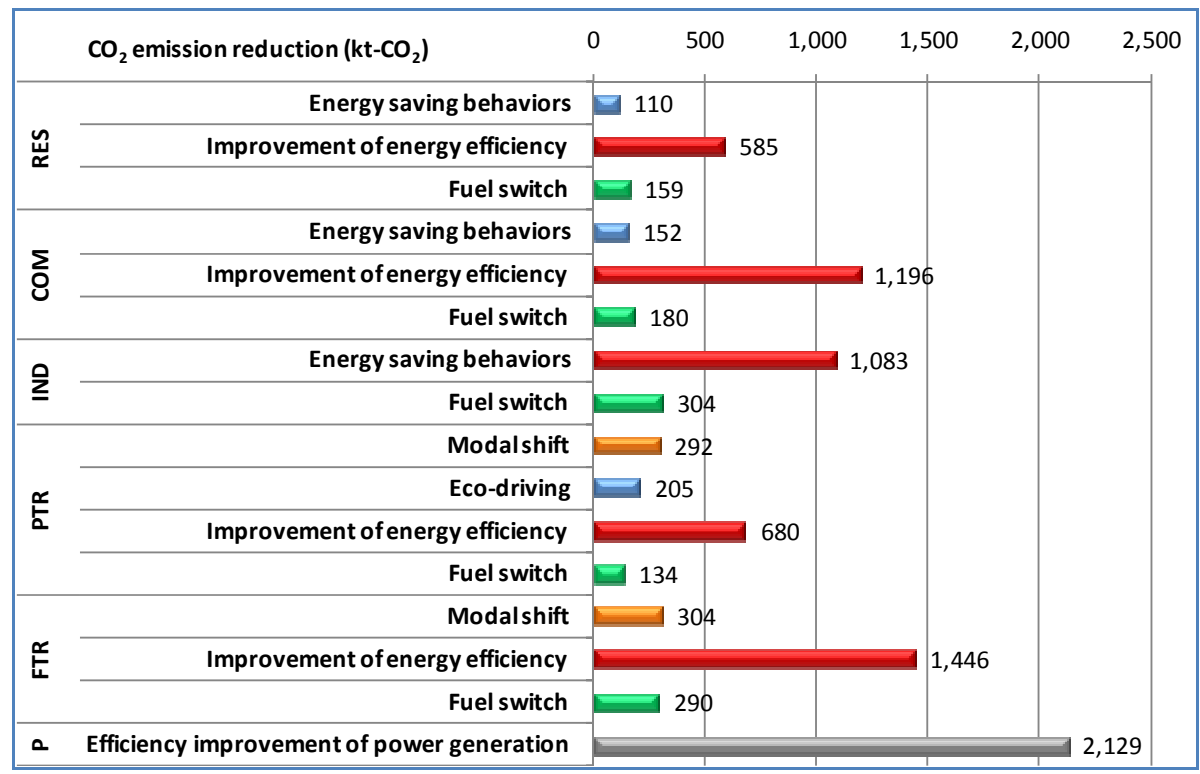

Fig. 14 Potential of $\mathrm{CO}_{2}$ emission reduction by measures in each sector. 
society, Iskandar Malaysia has to have new and bold policies to encourage and promote businesses and citizens and have to take countermeasures to lower the emissions levels. An example of the type of countermeasure which can be implemented is such as integrated green transportation, where public transportation system is improved, rail based and water based public transportation is introduced and also to have an efficient inter-modal interchange facility. IRDA (Iskandar Regional Development Authority) and the various stake holders together with researcher are now developing a low carbon blueprint for Iskandar Malaysia which will provide a dozen actions which are a list of various countermeasures which can be implemented by the local authorities in Iskandar Malaysia, and this will benefit industries, commercial sector, residents, public amenity and facilities and the general public.

\section{Conclusions}

In conclusion, this paper reviews the current scenario of $\mathrm{CO}_{2}$ emissions at the national level. Malaysia aims to be amongst the list of developed nations by 2020, therefore a lot that can be done towards moving the economy and people to a brighter future, and the move towards a low-carbon nation is one that it can not be overlooked. With the case study of Iskandar Malaysia, the authors can identify the current levels of $\mathrm{CO}_{2}$ emissions and forecast their future. With the suitable policies and strategies in planning and development, the set target of $40 \%$ reduction of $\mathrm{CO}_{2}$ emission per GDP by 2020 is able to be achieved. The role of the local authorities, government and town planners are essential here. Towards making the scenario with counter measure a reality, the authors have to design a framework or roadmap which will enable each mitigation measure become an action to be implemented within Iskandar Malaysia. This study worked the model to estimate the current (2005) and future (2025) $\mathrm{CO}_{2}$ emissions levels in IM. With these estimations, measures to lower the $\mathrm{CO}_{2}$ emission intensity were identified. In conclusion, the authors can say that a reduction of 9,250 kt- $\mathrm{CO}_{2}$ from $2025 \mathrm{BaU}$ to $2025 \mathrm{LCS}$ is achievable, this also continues to show that a $50 \%$ reduction of $\mathrm{CO}_{2}$ emission per GDP is achievable by 2025 with the low carbon scenario measure. This study can be applied at a national level so that a more sustainable kind of development can be achieved with the incorporation of a low carbon society to the planning.

\section{References}

[1] T. Delay, Low-Carbon Economy, The Carbon Trust, London, 2006.

[2] R.B. Gibson, S. Hassan, S. Holtz, J. Tansey, G. Whitelaw, Sustainability Assessment, Criteria and Processes, Earthscan, London, 2005.

[3] S. Bell, S. Morse, Sustainability Indicators, Measuring the Immeasurable?, Earthscan, London, 2008.

[4] S. Lehmann, The Principles of Green Urbanism, Earthscan, London, 2010.

[5] Town and Country Planning Department, National Physical Plan, Department of Town and Country Planning Department, Kuala Lumpur, 2006.

[6] Town and Country Planning Department, National Urbanization Plan, Department of Town and Country Planning Department, Kuala Lumpur, 2006.

[7] National Energy, Green Technology Policy, Ministry of Green Technology, Energy and Water, Putrajaya, Malaysia, 2010,

[8] Tenth Malaysia Plan 2011-2015, Malaysia Economic Planning Unit, Putrajaya, 2010.

[9] Second National Communication to the UNFCCC (United Nations Framework Convention on Climate Change), Ministry of Natural Resources and Environment Malaysia, 2011.

[10] Comprehensive Development Plan for South Johor Economic Region 2006-2025, National Treasury (Khazanah Nasional), Kuala Lumpur, 2006.

[11] Town and Country Planning Department Johor Structure Plan 2001-2020, Johor Town and Country Planning Department, Johor Bahru, 2003.

[12] K. Gomi, K. Shimada, Y. Matsuoka, A low-carbon scenario creation method for a low-scale economy and its application in Kyoto City, Energy Policy 38 (2010) 4783-4796.

[13] K. Gomi, Y. Ochi, Y. Matsuoka, A Systematic quantitative backcasting on low-carbon society policy in 
Kyoto City, Technology Forecasting and Social Change 78 (5) (2011) 852-871.

[14] H.C. Siong, Malaysian vision and pathway towards low carbon society (LCS), in: Proceeding of the 3rd Workshop of Japan-UK Joint Research Project "Roadmap to Low-Carbon World”, Tokyo, Japan, Feb. 2008.
[15] Y. Matsuoka, G. Kurata, T. Fujiwara, K. Shimada, K. Gomi, K. Yoshimoto, et al., Low-Carbon City 2025 Sustainable Iskandar Malaysia, in: Vise Chancellor Council \& Japan Society for the Promotion of Science, Group VII: The Panning of Urban Energy and Environmental Systems, Jan. 2009. 